\title{
Research on the Application of M-learning in Higher Education Lehui Huang $^{1,}$, Xinxin Wang ${ }^{2, b}$ \\ ${ }^{1}$ Education School, Jiangxi Science \& Technology Normal University, Nanchang, China \\ ${ }^{2}$ Education School, Jiangxi Science \& Technology Normal University, Nanchang, China ahlh8899@163.com; 'b1270731275@QQ.com
}

Keywords: M-learning; college education; M-learning model

\begin{abstract}
With the development of communication technology and network technology, M-learning has become a new learning mode following the digital learning and a new hot spot in the field of educational technology. Colleges still have many factors affecting M-learning while having a lot of advantages in the use of mobile devices. The paper analyzes the connotation of M-learning, discusses its application mode in college education, and puts forwards some suggestions in view of the influencing factors of M-learning, hoping to provide useful reference for the related research.
\end{abstract}

\section{Introduction}

With the development of communication technology and network technology, M-learning has become a new learning mode following the digital learning and a new hot spot in the field of educational technology. As a new convenient learning way, M-learning breaks the restriction of education object, education time and education space, and gives more freedom to learners, pointing out a new direction for the education and teaching reform in colleges and universities.

\section{The connotation of M-learning}

Mobile learning (M-learning) is a new learning mode following the digital learning. It refers to a new form of learning by using wireless mobile communication network technology and wireless mobile communication equipment to obtain education information, education resources and education service.

The core advantages of M-learning are: (1) flexible and convenient learning way. Learners can use fragmented to log in M-learning platform through smart phone or tablet computer anytime and anywhere to browse the latest information, read the new book and learn courses conveniently. (2) Advanced and efficient learning concept. M-learning courses adopt the latest LPM learning process management. The courses are divided into carefully refined chapters, supplemented by a large number of supplementary learning materials and added many share interactive sessions in the process, to prompt the students thinking in combination with the practical work and improving the learning effect while strengthening memory. (3) Complete mastery of learning effect. Through the key data statistics of students' learning materials download, experience sharing, login times and so on, the managers can understand the learners' learning habits and learning initiative, and then follow up and control their learning effect effectively. (4) Reduce the inputs of training equipment. In mobile era, everyone must have mobile phones and the popularity of smart terminals is increasing year by year.

\section{The application mode of M-learning in Higher education}

M-learning based on short message service. Sending and reading short messages is a common function of mobile devices. M-learning based on short message service is usually limited to the emotional communication between students and teachers, and some notice sending, such as, sending course notification, arrangement of examination or course information. It also can control and manage the teaching activities, such as providing guidance, support and encouragement. The 
M-learning based on short message is a mode of intermittent information transmission between round and round, which can not satisfy the browsing of continuous information.

M-learning based on web browsing. The development of wireless network bandwidth and mobile devices effectively overcome the shortcomings of M-learning based on SMS and open up the M-learning based on web browsing. In this mode, learners access to the internet via telecommunication gateway and access the server through the network protocol. It is similar with network distant learning. Just the way of the web browsing is carried out on the mobile device, similar to the digital learning resources transplanted to the mobile device, and you can browse the website, search resources and learn at anytime and anywhere.

M-learning based on digital portable equipment. M-learning based on digital portable equipment refers to the learning mode through playing audio and video by the use of digital portable devices (such as MP3, MP4 player, radio, podcast, etc). If you are a student majoring in English, you can use the function of smart phone to download English movies, English songs, English novels, and learn at anytime and anywhere. It is more important that it can be repeated playback.

\section{The suggestions of the application and promotion of M-learning in higher education}

Enhance the ability of students to use mobile learning devices. In traditional teaching, the teachers guides the students' learning process, that is to say, the students only need to carry on the study activity according to the teachers' instruction. However, a number of mobile learning devices spawned by the rapid development of modern science and technology put forward higher requirements on the ability of learners to use those equipments. This is because, in the teaching process of traditional classroom, teachers can guide learning at any time, but in the process of M-learning, students mainly depend on their autonomous learning ability and cognitive characteristics. Students should not only be good at grasping the key, but also do well in carrying out autonomous learning and cooperative learning. In addition, if the college students cannot understand the future employment pressure and the characteristics and requirements of M-learning, it is difficult to achieve good results. Therefore, they students recognize the future employment pressure, cultivate strong sense of crisis, fully improve their qualities and skills, and grasp the requirements and characteristics of M-learning, to maximize the promotion effect and level of M-learning.

Improve the college environment of M-learning. In addition to the subjective aspect, M-learning has very high requirements in the objective aspect. It requires the relevant M-learning has the characteristics of good mobility and easy access, so as to maximize the support of college teaching. However, from the point of view of mobile devices provided by the universities, it is difficult to achieve this point fully. For example, the mobile learning devices held by most college students are nothing more than smart phones, iphone, mp4, etc, which meet their demand to a certain extent. However, the defects of those mobile learning devices cannot be ignored, such as small capacity, relatively slow access speed, etc. due to the difference of regional economic and mobile learning environment, M-learning is greatly constrained. From the point of view of colleges, in order to form the mobile learning covering the whole campus and dormitory, it is necessary to adopt and develop related network and the main server with strong compatibility, which can provide more favorable access, related learning and teaching resources for M-learning to improve the college students'

M-learning to the high limit. For example, many schools already have the network equipment covering the whole campus, and provided more complete mobile device system in the multimedia classrooms, libraries, reading rooms and other places. In addition, the students' mobile learning equipments are also very advanced, for example, many students have mobile learning devices, including smart phones, mp4, etc, and the schools should try to provide them with a large capacity of related equipments and servers to enhance their access speed. Meanwhile, the learners' mobile learning environment should be improved constantly to maximize the effectiveness of mobile learning devices in colleges.

Establish systematic management. As so far, mobile learning is still in the process of exploration, 
and the research and practice in this area almost entirely depends on the learners' own initiative. Many colleges lack sound system to maintain the related systems and facilities of mobile learning, and still have a lot of work to be done in the system construction, such as teaching methods closely combined with tradition, how to carry on teaching design, etc. without perfect system for control and management, the development of M-learning is bound to have a lot of restrictions. From the point of view of the mobile network learning platform, the digital network learning platform should be combined closely to ensure the college students to share related information resources. In addition, it can also provide comprehensive and accurate information resources service for learners. For example, design the relevant service platform covering mobile learning resources, including the following sections: login, service, curriculum resources, education administration and other different modules.

Provide good technical support. With the rapid development of mobile technology, M-learning in higher education has gained more advanced technical support, such as 3G, 4G, WAP, WIFI, GPRS, etc. because of the development of wireless network, media delivery becomes more convenient and easy, and makes M-learning implemented at any time with high quality. However, if the necessary data network cannot be offered or technical failure cannot be treated timely, the effect of M-learning will be reduced greatly. Therefore, colleges should enhance the level and capacity of the team maintaining wireless network vigorously to provide good service for the M-learning. In addition, the colleges should improve the construction of the wireless network constantly, promote the transmission of learning resources, and improve the download speed of resources, so as to achieve information sharing by a variety of forms.

\section{Summary}

M-learning has become a hot research topic in the educational field. It broadens the channels of communication between teachers and students and gives new vitality to the traditional teaching mode. It proved that, reasonable mobile learning mode can provide rich, independent, and open learning space for learners, span time and space constraints, and realize the true personalized learning. Of course, there are some obvious problems in the application of M-learning in colleges. Therefore, we should take some corresponding countermeasures to provide excellent service and facilities for M-learning, so as to make M-learning well play its great role in colleges.

\section{References}

[1] Kai zheng, Jun Xu. Research on the construction and development of M-learning system in colleges and universities[J]. China audio visual education,, 2011(9):20-24.

[2] Qin Wang, Jun Wang. Research on the application status and development strategy of M-learning in colleges and universities[J]. China electric power education, 2013(8).

[3] Shaoting Song, Pengjiao Wang. Study on the application of M-learning based on smart phone in higher education[J]. China education information, 2009(23).

[4] Yushun Li, Ding Ma. Current station and trend of M-learning[J]. China information technology education, 2008(3):9-11.

[5] Shengquan Yu. M-learning: the new field of the contemporary e-learning[J]. China distance education, 2003(5):76-79.

[6] Brown JS, Collins A, Duguid P. Situated Cognition and the Culture of Learning[J]. Educational Researcher, 1989(1):32-42.

[7] Zhenfang Liu. M-learning is the new direction of the development of modern education technology[J]. China audio visual education, 2005(9). 